\title{
A nova era da comunicação: reflexões sobre a atual revolução tecnológica e seus impactos no jornalismo
}

\author{
BERNARDO KUCINSKI \\ Universidade Federal de Santa Catarina - bkucinski@usp.br \\ Físico e jornalista, é doutor em Comunicação e \\ pós-doutor pela University of London. Por mais de vinte anos, \\ lecionou na Universidade de São Paulo, onde se aposentou há cinco anos. \\ Entre 2003 e 2006, foi assessor especial da Presidência da República, \\ em assuntos de comunicação. É professor visitante da UFSC.
}

\section{Resumo}

O artigo é uma versão da conferência apresentada como aula magna do Programa de PósGraduação em Jornalismo da Universidade Federal de Santa Catarina (POSJOR/UFSC) em 13 de março de 2012. São problematizadas as bases que sustentam as práticas da comunicação na contemporaneidade e seus impactos nos modos de produzir e consumir jornalismo.

\section{Palavras-chaves}

Jornalismo, Mídia, Comunicação.

\section{Abstract}

The article is a version of the conference presented as the Master in Journalism from the University of Santa Catarina (POSJOR / UFSC) on March 13, 2012. Focuses on the foundations that underpin the practices of communication and their impact on contemporary modes of producing and consuming journalism.

\section{Keywords}

Journalism, Media, Communication. 


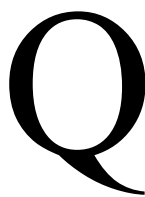
ue outro tema poderia escolher, para uma aula inaugural, se não a "destruição criadora”, para usar a expressão de Schumpeter (1985), que vem levando à ruína os grandes jornais, erguidos num passado não muito distante por um empresariado arrogante e todo-poderoso, e derrubando ao mesmo tempo, uma a uma, as demarcações do jornalismo como oficio?

Recorro, já nesta abertura, para afastar acusações de deslumbramento ou falta de rigor, à avaliação desta revolução de Rosental Calmon Alves, no livro agora lançado pelos professores Christofoletti e Karam e outros desta universidade ${ }^{\mathrm{i}}$ :

O modelo que se extingue é chamado por Rosental "ecossistema industrial", no qual ele aponta as seguintes características: escassez de informação, escassez de canais, altas barreiras de entrada de informação, altos custos de produção, tendência monopolista, comunicação vertical/unidirecional, limitação de tempo/espaço, pacotes fechados/estáticos, emprego de canais mono-mídia, audiência de massa, audiência passiva, pouco ou nenhum feedback/monólogo, produtor versus consumidor.

O novo modelo de jornalismo é batizado por Rosental de "Ecossistema digital". No qual ele aponta abundância de informação e de canais, baixas barreiras de entrada de informação, baixos custos de produção, mais concorrência, comunicação horizontal e multi direcional, sem limites de tempo/espaço, fluxos de informação aberta/dinâmica, canais multimídia, audiência diversa/mais nichos, audiência ativa, abundante feedback/conversação,mistura dos papéis de produtor e consumidor, o que nos EUA tem sido chamado de "prosumer". (TOGNOLLI, 2011: p. 64)

Não subscrevo necessariamente cada uma das definições de Rosental, porque ainda estamos no início desta revolução tecnológica. É muito cedo para se prever com algum grau de certeza a espécie de jornalismo que está nascendo. Mas endosso sem hesitar a sua conclusão geral. Diz ele:

A Revolução Digital impõe mudanças estruturais radicais que vão continuar nos próximos anos, décadas. Nunca uma revolução tecnológica afetou o jornalismo tanto e de forma tão abrangente. Já começou a ruptura dos modelos de negócio, de narrativas, de distribuição, de relacionamento com o público e com as fontes etc. As redes sociais mudaram o mundo e são o maior exemplo das mudanças extraordinárias que estão por vir. (op.cit.: p.64) 
Concordo e digo mais. A era virtual, além de reconfigurar de forma radical cada um dos meios e o conjunto da comunicação, revolucionou as formas de socialização do ser humano, as práticas políticas e o modo pelo qual as novas gerações se relacionam com o saber. No bojo dessa onda de inovações, emergiu todo um novo tipo de sociedade, repetindo-se, mas num intervalo de tempo muito mais curto, o que já havia acontecido com a invenção do motor e da indústria.

Na esfera da comunicação, trata-se da maior revolução nos meios de produção, registro, armazenamento, processamento e transmissão da informação, lazer e cultura em toda a história. Maior talvez que a própria invenção da escrita, que se deu gradualmente, numa escala de tempo de séculos, e a dos tipos móveis de Gutenberg, esses surgindo abruptamente, mas que logo se tornaram, como o chumbo do qual são feitos, em armaduras metálicas, limitando severamente a capacidade de expressão da imaginação humana.

No jornalismo, vivemos uma mudança estrutural tão profunda e ampla que alguns estudiosos, antes mesmo que se possa divisar seu horizonte de efeitos, já se referem a uma ruptura epistêmica. Uma situação na qual o referencial teórico clássico pouco serve para explicar o que se passa. Há um futuro da comunicação e um passado que nada diz sobre esse adiante. Algo parecido deve ter acontecido quando a invenção da arma de fogo destruiu impiedosamente e de supetão o universo de práticas e valores da cavalaria. Só que a ruptura de agora abrange toda a sociedade.

Nem mesmo McLuhan (1992), que anteviu algo do que hoje se passa quando formulou os conceitos de "aldeia global" e dos meios de comunicação como extensão do homem, poderia imaginar a escala desse processo.

A comunicação virtual tornou-se mais do que uma extensão dos nossos sentidos, tornou-se o locus formativo do ser humano, seu contato com o mundo e seu caldo de cultura, desde os seus primeiros passos, jogando a um segundo plano agências formativas tradicionais, como a família, a igreja e a escola.

No lugar da família e da escola, a criança mergulha numa vasta nebulosa informativa cujas principais características são a comunicabilidade total, contínua e móvel, e a abolição quase completa da esfera privada. Valendo-se da própria 
virtualização, o mesmo capitalismo da "destruição criadora" cria novos sistemas impessoais e invisíveis de controle e dominação que operam sob formas sutis, subliminares, alcançando a pessoa na sua intimidade, no seu inconsciente, nas instâncias de sua pré-percepção, como que remodelando-as numa "nova natureza". Tudo é devassado, até a mais íntima camada da vida pessoal, um fenômeno com vastas e perturbadoras implicações éticas, sociológicas e educacionais.

O mais surpreendente é a naturalidade e passividade com que tudo isso é apropriado pelas novas gerações, o que aponta para uma hipótese adicional: a de que a comunicação virtual é mais natural e adequada à capacidade imaginativa do ser humano do que as formas anteriores limitadas pela rigidez da máquina e da matéria.

No jornalismo, especificamente, as conseqüências mais dramáticas dessa revolução não são o declínio ou a morte inevitável dos jornais impressos. Mesmo porque a maioria conseguirá se reconstruir como veículos virtuais, obtendo índices de leitura até superiores aos da era impressa.

O mais importante é que esses jornais nunca voltarão a ser as instituições poderosas da sociedade civil, criadas no século XIX por burguesias portadoras de projetos nacionais e imperiais, donas da comunicação de massa e, através dela, detentoras do monopólio da produção de significados e percepções na esfera pública.

Um ocaso que não resulta apenas da ruptura digital, mas, sobretudo, do término de uma travessia histórica. Do fato de que até mesmo o capital se virtualizou, assumindo natureza global e fugidia, da mesma forma que a moeda virtual, dispensando (e até se opondo a) ordenamentos de poder locais. Não por acaso, esta revolução coincide com o predomínio do capital financeiro no sistema mundial de poder, circulando sem compromissos sociais ou culturais. É o esgotamento de toda uma narrativa e das respectivas usinas produtoras que lhe davam o indispensável lastro de opinião pública - os grandes jornais da burguesia.

Nem as redações dos jornais, fragmentadas e debilitadas, manterão o papel de centros de criação do saber jornalístico. Esse é, para nós, jornalistas e estudiosos do jornalismo, o prognóstico mais preocupante: se o jornalismo é também uma forma social de conhecimento, como o definiu em sua época o professor desta universidade, 
Adelmo Genro Filho (1982), de onde nascerá esse conhecimento com o esvaziamento das redações?

Já hoje, além do encolhimento dramático das equipes, nos veículos mais ativos, o processo coletivo de criação do conhecimento jornalístico cedeu lugar à terceirização da produção e à compartimentação dos saberes. Mesmo na esfera das revistas, que ao contrário dos jornais se multiplicam na era virtual, num processo incessante de segmentação e pulverização do mercado, a produção jornalística foi toda ela terceirizada. A relação de trabalho dominante do oficio é hoje o free-lancismo e as redações tornaram-se virtuais.

$\mathrm{Na}$ nova esfera pública da era virtual, os jornalistas não mais detêm o monopólio da fala e da mediação. Perderam sua função principal. Os grandes momentos de formação de percepções e o de mobilização política deslocaram-se para essa nova esfera pública, na qual os jornais - mesmo os digitais - são coadjuvantes secundários, não mais os condutores do processo. A internet mudou as relações de poder, permitindo, como diz Manuel Castells (1999), que a sociedade civil se manifeste sem ter que pedir licença aos meios tradicionais de comunicação de massa.

Vivemos, é verdade, a fase de transição entre o antigo e o novo, na qual o poder político dos grandes jornais impressos ainda se manifesta aqui e acolá, por vezes com virulência. Mas definham rapidamente, em proporção à sua debilitação econômica. Como animais em extinção, alguns só sobrevivem hoje graças a subsídios e proteção do Estado. Não por acaso, formam hoje um bloco ideologicamente homogêneo e reacionário de defesa dos interesses dominantes e do poder econômico. Essa é outra ruptura entre o que se poderia chamar de nova esfera pública, de vocação contrahegemônica, e a velha esfera pública dos meios de comunicação tradicionais.

A comunicação virtual não depende do capital das grandes empresas e seus interesses. Não precisa de florestas de eucaliptos, fábricas de papel de imprensa, frotas de caminhões e rotativas gigantescas. Não há mais tipos de chumbo, nem linotipos, nem filmes fotográficos, nem emulsões de revelação, nem malotes por avião para o envio do material. Já nem teclado material ou cabos condutores haverá, pois já chegou o teclado virtual e a comunicação infra-vermelha. Tudo é produzido, processado, disseminado e absorvido imaterialmente. 
É um novo modo de produção barato e descentralizado. No entanto, com alcance e recursos de manejo da informação infinitamente mais amplos, do que os do modo convencional. E por ser barato e interativo, é também menos dependente das mediações dos quadros de confiança dos donos do capital. Essas são apenas algumas das características revolucionários da comunicação na era virtual.

A força propulsora desta revolução - que não se dá apenas na comunicação - é a inovação tecnológica. Não uma novidade, nem duas, mas um conjunto enorme de desenvolvimentos fundamentais na microbiologia e microfísica que, combinados, criaram ferramentas e processos antes inimagináveis. Na esfera da comunicação, os principais são o cérebro eletrônico, a World Wide Web (WWW), a fibra ótica, o satélite artificial, a digitalização, o telefone celular e os tablets.

Nas outras esferas, são a engenharia genética, os transplantes de órgãos vitais, a reprodução fora do útero, a clonagem. Conceitos fundamentais do nosso entendimento clássico foram destroçados por essa avalancha de inovações, entre eles as definições de vida, de morte e de maternidade.

É o capitalismo se renovando de modo espetacular, como já o havia feito quando a invenção do motor multiplicou suas forças produtivas numa escala sem precedentes. Também, então, deu-se uma sucessão de inovações que, começando no manejo da terra e atingindo o apogeu com a invenção do motor, tornaram possível a produção industrial em grande escala nos teares mecânicos e nas metalurgias.

A máquina destruiu o mundo do artesão. A produção migrou das pequenas oficinas para as grandes fábricas, verdadeiros campos de concentração da produção operária, em torno de máquinas e de uma linha de montagem. Nos transportes, a invenção da locomotiva reconfigurou paisagens em todos os continentes.

No jornalismo, esse modo de produção capital intensivo atingiu o seu apogeu com a invenção das rotativas, centrais de produção gigantescas, demandando para cobrir seus custos, tiragens também gigantescas. As empresas jornalísticas assumiram a forma de grandes empresas de ponta, comandando a um só tempo lucro e poder político.

Mas a atual revolução tecnológica se dá numa direção oposta à da revolução industrial, em algumas esferas atuando como aríetes demolidores do sistema oriundo da revolução industrial. Já foram desmontadas pela virtualização as indústrias fonográficas, 
de material fotográfico e de máquinas de escrever; hoje, se inicia o desmonte das indústrias de livros impressos e de máquinas de projeção cinematográfica.

Se a revolução industrial levou à concentração da produção, sob o domínio da máquina, portanto do capital, com isso criando a fissura entre trabalho e capital, a atual revolução nos liberta da máquina, desmaterializa os processos produtivos e devolve ao trabalho a possibilidade - pelo menos a possibilidade - de uma autonomia relativa.

Trata-se ao mesmo tempo de um novo salto novo na capacidade da forças produtivas e de uma mudança radical em sua direção. É como se todo o desenvolvimento das forças produtivas da Antiguidade até ontem tivesse se dado em torno de um sistema equivocado e sufocante de amarras mecânicas, do qual apenas hoje começamos a nos desvencilhar. É como se tudo o que antes aconteceu fosse apenas uma pré-história do que hoje começa a acontecer.

É verdade que ao mesmo tempo se dá uma concentração ainda maior nos mercados e nos sistemas de circulação. É a resposta dos detentores do capital ao potencial autonomista e libertário das novas tecnologias. Por isso, vivemos hoje também uma era de megafusões, em que apenas duas ou três empresas procuram o domínio mundial da circulação. Na esfera da comunicação, todos esses novos monopólios são, não por acaso, empresas surgidas da inovação, as empresas ponto com: Amazon, Apple, Google, entre outras.

A revolução de hoje cria um sistema que não dispensa a linha de montagem, mas a torna marginal no processo geral de criação e apropriação de valor. Uma etapa do capitalismo na qual o que mais se produz é conhecimento e serviço - não a mercadoria. No jornal da era virtual, há serviço, na forma de informação, mas não há mercadoria, nem na forma material de um maço de papel impresso, nem na forma mercadológica de uma comercialização da notícia, motivo pelo qual poucos jornais digitais conseguem a viabilidade econômica, embora alcançando índices espetaculares de acesso. Como disse o próprio Marx, "tudo o que é sólido se desmancha no ar."

Há uma relação direta entre o novo grau de desenvolvimento das forças produtivas ensejado pela inovação e o colapso do regime soviético, que por sua natureza autoritária era infenso à inovação e ao empreendedorismo schumpeteriano. Há uma 
Estudos em Jornalismo e Mídia - Vol. $9 \mathrm{~N}^{\circ} \mathrm{I}$ - Janeiro a Junho de 2012 ISSNe 1984-6924

relação direta entre a natureza das inovações desta evolução tecnológica e os procedimentos do sistema chamado neoliberal.

Esta revolução marca o triunfo de um novo capitalismo, com todo o seu rol de iniquidades, no entanto mesmo assim imbatível e inconteste, impondo seus ditames a sociedades inteiras que não sabem como lhe resistir. Não por acaso deu-se o colapso das utopias que se propunham a acabar com o capitalismo. Primeiro, foi-se a utopia anarcosindicalista, de cunho libertário, contra a opressão das fábricas e toda forma de autoridade; depois, a da revolução comunista, essa escorada numa teoria científica da história.

A ausência hoje de uma utopia é outra característica preocupante desta transição, e com implicações profundas no jornalismo. Pois, o que é ser jornalista sem abraçar alguma forma de utopia, algum tipo de preferência ou crença no advir de numa sociedade melhor? Há séculos, as utopias movem contingentes e pessoas. Uma utopia criou o cristianismo, uma utopia levou à descoberta do Novo Mundo pelos europeus, o que por suas vez levou ao surgimento de novas utopias. E, de repente, não há mais metanarrativas...

O avanço civilizatório parece se dar hoje de modo incremental, quase imperceptível, nos costumes, nas novas leis de proteção à infância e ao meio ambiente, nos novos recursos da medicina terapêutica, nas novas posturas de tolerância ao diferente. Mas tudo isso se dá num espaço consentido, sem que as macro-estruturas de poder sejam afetadas no seu essencial. Sem metanarrativas.

Talvez a ausência de metanarrativas explique o conformismo geral frente a manifestações da dominação mais abstratas, menos perceptíveis no cotidiano. Por exemplo, frente ao domínio capital financeiro e à destruição da arquitetura monetário erguida em Bretton Woods com alguma base na racionalidade, dando lugar a esse grande cassino da especulação financeira que hoje vemos.

Espanta-me que o pensamento dominante na academia brasileira, ainda pretensamente marxista, se recuse a aceitar a legitimidade histórica do neoliberalismo e o veja como uma espécie de truque do grande capital para se apropriar de riquezas nacionais ou com mais liberdade explorar a mais-valia operária e não, como de fato é, o 
corolário ideológico das inovações tecnológicas, do novo estágio de desenvolvimento das forças produtivas.

O próprio Marx, ele sim, um marxista, sustentou que a tecnologia revela a relação do homem com a natureza, o processo social de produção da vida e das relações sociais. É nesse plano de análise que devemos analisar os nexos entre novas tecnologias e ideologia neoliberal e situar as propostas e valores do neoliberalismo, por mais odiosos que muitos deles nos pareçam, tais como a competição extrema, a exacerbação do individualismo e o desmonte das estruturas sociais de apoio aos mais frágeis.

Ora, o que menos importa hoje, no conjunto das contradições e conflitos gerados por esta revolução, é a mais-valia operária. Esta se resolve e é absorvida no âmbito da fábrica, sem repercussão no conjunto da sociedade. Desde os eventos de maio de 1968 na França - e já lá se vão mais de 40 anos - ficou claro que o operariado fabril deixou de ser a força social condutora da história nas economias centrais. A própria identidade de classe está hoje diluída em papeis multifacéticos. O operário é também o investidor, o proprietário. No Brasil, esse papel se esgotou, em nosso caso de modo magnífico, nas grandes greves de 1978 a 1980 que derrubaram a ditadura. Isso foi há mais de trinta anos.

Que ninguém se iluda! Vivemos hoje uma nova fase na qual as formações políticas das mais diversas naturezas adotam os mecanismos típicos do capitalismo neoliberal, entre os quais as privatizações, as terceirizações, a propriedade privada, os salários diferenciados segundo o mérito, e a liberdade total de movimento de capitais.

Nesse cenário, há contradições novas e um protagonismo distinto do que aprendemos nos manuais simplificadores da antiga sociologia. Quais são as novas contradições? A principal delas, creio, é entre os interesses gerais de uma sociedade precarizada, na qual serviços públicos, mesmo os mais essenciais foram mercantilizados, e um Estado totalmente controlado pelo capital financeiro.

Outra contradição importante é entre o desemprego crônico massivo de um lado e a sedução permanente do consumo, de outro. E a terceira grande contradição de hoje se dá no grau desigual de desenvolvimento de tudo isso em escala global, impulsionando de modo dramático as ondas de migração da África e Ásia em direção ao centro rico do capitalismo. 
A luta de classes se transfigurou numa luta dos sem classe. É nas praças onde se reúnem os desempregados e os jovens casais que não podem comprar uma moradia, ou os funcionários públicos precarizados, que se manifestam hoje as contradições do neoliberalismo. Nas praças do Cairo, de Atenas, de Roma e de Barcelona...

E quem são os condutores da luta social? Todos e ninguém. Nesse cenário, o operário de fábrica, estável, protegido por seu sindicato, que faz greve ganhando marmita e camiseta estampada, é até um privilegiado. O novo organizador não é mais o sindicato, nem o partido político, é o Facebook. O mobilizador é o Twitter, o conscientizador é o Wilkileaks e a Al Jazeera; a direção geográfica do comício é dada pelo Google Earth. As palavras de ordem não são impressas em panfletos, são digitadas em mensagens de celular. A reunião não leva meses para ser organizada, ela surge como que por geração espontânea, de um dia para o outro. Mas é uma esfera pública frágil. Se antes a comunicação política era instrumento de uma força política já organizada, na era virtual, a comunicação virtual tenta organizar em força política uma massa heterogênea e deserdada de partidos e ideologias.

Suas manifestações tem todas as características do instantaneísmo, voluntarismo, carência de uma bandeira transcendente e unificadora. O predomínio do individualismo como valor limita tão severamente o alcance dessa nova esfera pública, que talvez nem seja adequado defini-la por esse conceito.

Vamos nos deter agora nas implicações mais diretas deste cenário no jornalismo. A primeira constatação conceitual é a de que a comunicação virtual deu a cada pessoa o poder de informar na esfera pública, estabelecido na Carta da ONU como distinto do direito de ser informado.

Houve um avanço civilizatório significativo, neste caso mais do que meramente incremental na esfera dos direitos humanos básicos. Hoje, cada pessoa minimamente capacitada, fala por si, sem precisar da mediação do jornalista, pode ter o seu blog ou o seu site, ou se tornar um produtor cultural, ou contestar as opiniões do jornalista. A matéria jornalística deixou de ser a palavra final, para ser tão somente a iniciadora de um debate. O próprio ethos do jornalista muda. Ele passou a ser emulado não pela qualidade de sua matéria e sim pelo grau de polêmica por ela suscitado, medido pelo número de intervenções na versão digital do jornal. 
As transformações são muitas, profundas e ainda estão em curso. Mas essa revolução tecnológica já derrubou as seguintes demarcações do jornalismo e com elas a própria definição do jornalismo como um campo caracterizado por uma ética própria e papéis claramente atribuídos:

1) A demarcação entre comunicação pública e privada. $\mathrm{Na}$ era virtual, não sabemos se a comunicação é pública ou privada. Até hoje, não se fez e talvez nunca se faça um protocolo que estabeleça essas regras para a internet e as redes sociais.

2) Sumiu a demarcação entre comunicação simples e comunicação de massa. Mensagens pessoais ou individuais, subitamente, alcançam escalas de acesso massivas.

3) Sumiu a demarcação entre emissor e receptor. Todos são emissores e receptores. O leitor interage, questiona, intervém e acaba se tornando um autor ele mesmo. A interatividade não tem limite na nova tecnologia.

4) Da mesma forma, não há mais distinção clara entre produtor e consumidor. Embora ainda exista o produtor como indivíduo e como empresa, qualquer um também pode produzir, até mesmo comercialmente; e mais, o próprio consumidor cria continuamente novas ferramentas de produção digital; o usuário é também um inventor.

5) Rompe-se o conceito de periodicidade, característica fundamental demarcadora do produto jornalístico, até então definido como aquele que tinha os atributos da novidade, interesse público, difusão e periodicidade.

6) Sumiram todas as demarcações entre diferentes meios de transmissão ou plataformas escritas, gráficas, sonoras, estáticas ou móveis. Tudo se funde, tudo se mistura, tudo interage nos mesmos meios e plataformas.

7) Ficou fortemente reduzida a demarcação entre ser jornalista e não ser. Quem é na internet o jornalista? E quem não é? E o que ele pode fazer e o que não pode? O blog é jornalismo, ou não é? E onde é que fica a ética jornalística, um das mais importantes fios condutores nessa teia de regras que se chama jornalismo?

8) Reduziram-se ainda mais as demarcações entre informação, propaganda e entretenimento, com implicações diretas na ética com oficio e na forma de gerenciamento das empresas de comunicação.

9) Desapareceu - paradoxalmente - o conceito de notícia como mercadoria. Mercadoria é conceito-fundador do sistema capitalista e notícia como mercadoria é 
categoria demarcadora do jornalismo de mercado assim como da definição de jornalismo como forma de conhecimento fundada no singular, fundada no fato recortado nitidamente no tempo e no espaço. Na era virtual, ao ser acessada, a informação não é consumida, ao contrário, se multiplica, como no milagre da multiplicação dos pães. A saga do capitalismo, lembra David Harvey (2011), está repleta de paradoxos. Esse é um deles. O leitor lê a notícia e em seguida, com um mero apertar de botões, a encaminha para uma lista de dez ou cem amigos ou mil membros de uma lista. Cada um deles pode fazer o mesmo. Ao consumi-la, ele a multiplicou. A notícia, na era virtual, não é mais a mesma mercadoria da era material da informação. Daí a dificuldade dos jornais virtuais de se autofinanciarem. Mais importante ainda é perda de demarcação da notícia também por força do fim da periodicidade do produto jornalístico, já que na era virtual informação é um fluxo incessante e sempre inacabado.

Termino esta fala com uma pergunta e uma nota de otimismo. A pergunta é a seguinte: se a autonomia do trabalhador intelectual em relação ao capital é um dos traços centrais da nova revolução tecnológica, manterá ele essa autonomia, ou será subjugado por algum novo mecanismo de poder do capital?

A nota de otimismo está inspirada numa troca de mensagem com meu amigo jornalista e filósofo Nivaldo Manzano que leu o rascunho desta conferência, e disse:

No século dezoito, o trabalhador foi despojado pelos donos do capital de seus instrumentos de produção. Em resposta, o trabalhador - que jamais conseguiu alienar-se inteiramente de sua própria criatividade reagiu no plano ideológico com a utopia do socialismo, até que pudesse, no plano real, por força do desenvolvimento do capital, recuperar a sua criatividade, que se expressa, por exemplo, na criação individual e livre do software. Como se sabe, o software é uma máquina dotada da propriedade física de operar algoritmos, susceptíveis, por definição, de incorporar a criação de todo instrumental inteligente de que o ser humano necessite na construção de sua vida material e cultural... os softwares são os instrumentos de produção que fogem ao controle do dono do capital porque resultam de uma construção puramente intelectual, imaterial, insusceptível de ser aprisionada por quem quer que seja, como inteligência em estado puro que é. Com a criação do software, a inteligência do trabalhador agora associada indissoluvelmente a seu instrumento de trabalho, saltou para fora dos muros da fábrica para juntar-se à multidão na praça da internet - e para a linha de montagem não voltará jamais. 
Vamos torcer para que as previsões do filósofo se confirmem, e que o novo jornalismo a emergir ao final desta revolução virtual, seja predominantemente libertário, e livre dos controles do capital. Vai depender muito da vontade das novas gerações de lutarem pela manutenção do caráter libertário das novas tecnologias, de sua capacidade de se realizarem através desses instrumentos de forma também libertária, e de resistirem às tentativas de controle dos mercados pelas gigantes ponto.com

Eis aí, sem querer, a proposta de uma nova utopia.

\section{Referências Bibliográficas}

CASTELLS, Manuel. A Era da Informação: economia, sociedade e cultura. São Paulo: Paz \& Terra, 1999 GENRO FILHO, Adelmo. O segredo da pirâmide. Porto Alegre: Tchê, 1982

HARVEY, David. O enigma do capital. São Paulo: Boitempo, 2011

MCLUHAN, Marshall. Os meios de comunicação como extensão do homem. São Paulo: Cultrix,1992

MARX, Karl \& ENGELS, Friedrich. Manifesto Comunista. IN: BOGO, Ademar. Teoria da Organização Política. São Paulo, Expressão Popular, 2005

SCHUMPETER, Joseph A. (1912). A Teoria do Desenvolvimento Econômico. São Paulo: Editora Abril, Coleção Os Economistas, 1985

TOGNOLLI, Claudio Julio. Rosental e o novo modelo midiático. IN: CHRISTOFOLETTI, Rogério; KARAM, Francisco José. Jornalismo investigativo e pesquisa científica: fronteiras. Florianópolis: Insular, 2011 
i CHRISTOFOLETTI, Rogério; KARAM, Francisco José (orgs.) Jornalismo investigativo e pesquisa científica: fronteiras. Florianópolis: Ed. Insular, 2011

ii MARX, Karl \& ENGELS, Friedrich. Manifesto Comunista. IN: BOGO, Ademar (org.) Teoria da Organização Política. São Paulo: Expressão Popular, 2005. 